Revista de Filosofía

ISSN: 0034-8244

https://dx.doi.org/10.5209/resf.68168

\title{
Formatividad e interpretación en la estética de Luigi Pareyson
}

\author{
Fabrizio Acciaro ${ }^{1}$
}

Recibido: 13 de agosto de 2017 / Aceptado: 28 de marzo de 2019

Resumen. Formatividad es el concepto clave de la estética de Luigi Pareyson, pero también de su hermenéutica filosófica. El artículo no se propone ilustrar la teoría estética de Pareyson sino: analizar en qué consiste esa formatividad intrínseca a toda actividad humana (primera parte); aclarar porqué la formatividad nos obliga a concebir el conocimiento como interpretación y, por tanto, a legitimar la hermenéutica (segunda parte); señalar algunas implicaciones de tal hermenéutica susceptibles de importantes y fecundos desarrollos (conclusiones).

Palabras clave: Formatividad; interpretación; hermenéutica; estética; Pareyson.

\section{[en] Formativity and interpretation in Luigi Pareyson's aesthetics}

\begin{abstract}
Formativity is the key-concept of Pareyson's aesthetics but of his philosophical hermeneutics too. The paper does not explain the aesthetic theory of Pareyson, but: analyze what that formativity intrinsic to every human activity is (first part); enlighten why formativity bind us to conceive knowing as interpretation (second part); indicate some implications of this hermeneutics admitting important and fruitful developments (conclusions).
\end{abstract}

Keywords: Formativity; interpretation; hermeneutics; aesthetics; Pareyson.

Sumario: 1. Formatividad; 1.1. La forma formante como guía del proceso formativo; 1.2. La ejemplaridad de la obra; 1.3. "Imitación" pareysoniana, "repetición" heideggeriana; 2. Interpretación; 2.1. Metafísica de la forma e incremento del ser; 3. Conclusiones; 4. Referencias bibliográficas.

Cómo citar: Acciaro, F. (2020): “Formatividad e interpretación en la estética de Luigi Pareyson”, en Revista de Filosofía 45 (1), 87-104.

1 Departamento de Filosofía

Pontificia Universidad Católica de Puerto Rico

facciaro@hotmail.com 


\section{Formatividad}

A pesar de que Pareyson formule su teoría de la formatividad a partir de la reflexión sobre la experiencia artística y en términos de teoría estética, el mismo autor nos advierte que su obra pretende tener un alcance mucho mayor, puesto que se trata de "un libro filosófico que, aun tratando de estética y de problemas del arte, podría ser enteramente transcrito en términos de filosofía general, válida también para otros campos de experiencia" 2 . En efecto, es una misma formatividad la que actúa tanto en la producción artística como en la producción técnica, en la actividad práctica como en la actividad cognoscitiva ${ }^{3}$.

"Formar, por tanto, significa «hacer», pero un hacer tal que, mientras hace, inventa el modo de hacer." Así define Pareyson la formatividad: producción que es, al mismo tiempo e inseparablemente, invención. En esta definición hay que subrayar en primer lugar que el hacer coincide con la entera existencia del hombre: vivir es hacer. Cualquier iniciativa, actividad, relación se realiza mediante operaciones que a su vez se concretan en obras 5 . Ciertamente esto es más evidente en aquellas actividades que son específicamente productivas, como por ejemplo la fabricación de un utensilio, pero no es menos cierto en el caso del pensar o del actuar, puesto que también el resultado de estas actividades - un pensamiento, una teoría, un texto, o bien un gesto, una acción, una empresa- es una obra ${ }^{6}$.

2 Pareyson (2005), p. 217. Esta cita es de nuestra traducción puesto que no aparece en la versión castellana, la cual ha sido realizada a partir de la primera edición de la obra, la de 1954, que fue modificada parcialmente en las ediciones posteriores. En lo que sigue, todas nuestras referencias (a excepción de un par de ellas) serán a la edición castellana: Pareyson (2014), que desde ahora en adelante indicaremos con la sigla ETF.

3 En propósito, así escribe Cristina Coriasso: "Pareyson mantiene clara la distinción entre poética y estética y considera a esta última como un ámbito en el que se tratan asuntos que atañen a toda la filosofía. (...) La estética de Pareyson no puede ser considerada como un ámbito especializado al margen de los otros intereses filosóficos, sino como la piedra angular del entero edificio que este construye: se trata de una estética hermenéutica, lo que significa que la concepción del proceso de producción de la obra y de lectura de la misma, o dicho con sus palabras, la «formatividad» de la obra, solo puede comprenderse como el más claro y quizá evidente proceso de interpretación en que consiste todo conocer humano", Coriasso (2014), p. XIV (subrayado nuestro). De otro aviso es Francesco Paolo Ciglia, para el que la meditación pareysoniana sobre la estética representa más bien "una continuación, una valorización y una profundización radical, de una teoría hermenéutica que ya venía claramente estructurándose durante la confrontación de nuestro pensador con el existencialismo europeo", Ciglia (1995), p. 107. De la tesis de Cristina Coriasso también difiere Francesco Marino, quien considera que, paralelamente a la estética, otro camino que llevó a Pareyson hacia la ontología de lo inagotable fue el problema de la historiografía filosófica, es decir, el problema del valor especulativo de las filosofías del pasado para la actualidad; más aún, la tesis de Marino es que la exigencia de concebir la verdad como inagotable llegó a imponerse a un cierto punto solamente en fuerza de este problema; cf. Marino (2015), p. 20 (pero el entero capítulo cuarto de la monografía de Marino está dedicado a ilustrar esta tesis). Por nuestra parte, convenimos con Marino en que la estética no ha sido el primero ni el único camino que condujo Pareyson a la hermenéutica; no obstante, nos parece que el papel fundamental de la estética, al que se refiere Cristina Coriasso, no concierne tanto la génesis de la hermenéutica en el itinerario especulativo de nuestro autor cuanto, por decirlo así, el modo de funcionar de la misma; en otras palabras, para Pareyson la interpretación es esencialmente un proceso formativo y la Estética es el único lugar donde nuestro autor ilustra explícitamente en qué consiste un tal proceso (aunque sea bajo una perspectiva particular: la de la producción y la lectura de la obra de arte).

4 ETF, p. 105 (subrayado de Pareyson).

$5 \quad$ Así lo explica Pareyson: “(...) todos los aspectos del obrar humano, desde los más simples a los más complejos, tienen un carácter ineliminable y esencial de formatividad. Las actividades humanas no pueden ejercitarse si no es concretándose en operaciones, es decir, en movimientos destinados a culminar en obras" (ibíd., p. 71).

6 Escribe nuestro autor: "Sea cual sea la actividad que se pretende ejercitar, siempre se trata de plantear problemas, constituyéndolos originalmente a partir de los datos informes de la experiencia, y de encontrar, descubrir, es más, inventar sus soluciones; se trata siempre de concluir y llevar a término operaciones, es decir de producir 
Por otra parte, en tanto que resultado de una actividad formativa, toda obra es una forma: posee determinada figura o configuración. Pero la forma de la que habla Pareyson no coincide con la forma de tradición platónico-aristotélica, en primer lugar, y sobre todo, porque no es pura inteligibilidad sino organismo ${ }^{7}$, en el que no hay distinción posible entre materia y forma. La forma-obra pareysoniana no es resultado de la unión (a posteriori) de una materia y una forma preexistentes y originalmente separadas, sino que éstas, por decirlo así, "nacen juntas"8, en el sentido de que se van definiendo recíproca e inseparablemente a lo largo del proceso formativo: la forma toma forma venciendo las resistencias de la materia y aprovechando las posibilidades que ésta le ofrece, así como la materia, por su parte, se utiliza o se descarta, se manipula, moldea y organiza de una manera u otra, según lo requiera la forma emergente paso a paso.

Es en este sentido que la formatividad, mientras hace, inventa el modo de hacer: su hacer no es aplicativo sino justamente formativo, y esto, de nuevo, significa que no consiste en la mera ejecución de una regla o principio prestablecido, sino en el descubrimiento, hallazgo e invención de su propia regla o principio interno. Por lo mismo, la obra no ha de ser concebida como copia de algún modelo al que supuestamente tendría que adecuarse, sino que su formación obedece a su propia ley de organización interna. De ahí también el que cada obra sea novedosa y singular: su forma no precede su producción, sino que es su resultado, resultado de un personalísimo modo de formar.

Todo esto es particularmente evidente en el caso de la obra de arte, puesto que ésta consiste en la producción de algo que antes no existía y lleva impreso el sello inconfundible de su autor, pero también atañe al producto de toda actividad humana: "Toda operación humana es siempre formativa, y también una obra de pensamiento y una obra práctica requieren el ejercicio de la formatividad. Una acción virtuosa [por ejemplo] debe ser inventada tal como la requiere la ley moral, en aquella determinada circunstancia, y debe ser ejecutada y realizada con un movimiento que a la vez invente su mejor modo para realizarla" .

Como ilustra el ejemplo recién mentado, vale la pena observar que la formatividad representa una alternativa al modo de pensar que podríamos llamar "deductivo". Según este esquema de pensamiento, el juicio consistiría en la aplicación de una ley general, que se supone ya dada, a un problema particular (en este caso, el problema práctico de la acción virtuosa). Pero la aplicación no resulta tan fácil como se supondría y, sobre todo, no siempre es unívoca, sino que da lugar a distintas soluciones. Es entonces cuando se habla de un "conflicto entre las interpretaciones",

realizando, cumpliendo, ejecutando, y de recoger el movimiento de invención en una obra que se esboza y se construye en función de una ley interna de organización; se trata siempre de hacer, inventando al mismo tiempo el modo de hacer (...) En definitiva, el obrar, sea cual sea la actividad que en él se especifica, implica siempre ese proceso de producción e invención en que consiste el formar, y todas las obras, en cuanto logradas, son formas dotadas de independencia y ejemplaridad" (ibídem).

$7 \quad$ Así escribe Pareyson en el prefacio a su Estética: “(...) por forma, entiendo organismo, viviente de una vida propia y dotado de una legalidad interna: totalidad irrepetible en su singularidad, independiente en su autonomía, ejemplar en su valor, conclusa y a la vez abierta en su definición que encierra un infinito, perfecta en la armonía y unidad de su ley de coherencia, entera en la adecuación recíproca entre las partes y el todo" (ibíd., p. 1).

8 La indisolubilidad de materia y forma es para Pareyson un "principio" constitutivo de la obra de arte: "Intención formativa y materia del arte van, por tanto, tan poco separadas que se debe más bien decir que nacen a la vez" (ibíd., p. 95). Pero como ya se ha dicho, ese mismo principio aplica a toda obra en general.

$9 \quad$ Ibíd., p. 73. 
pero tal expresión conlleva, por lo regular, la asunción implícita de que no debería subsistir ningún conflicto si la interpretación, en lugar que ser tal (es decir, "mera interpretación"), fuera la solución "verdadera": la única buena, correcta y adecuada, como única es la ley de la que se deriva. Mirada así, queda claro que la interpretación adquiere un tinte negativo que la aproxima a la simple opinión en contraste con la objetividad de lo verdadero. Pero ¿es esta la única manera, o la manera más razonable, de concebir nuestra relación con la verdad y a la vez el estatuto de la interpretación? ¿Es tal modelo "deductivo" de pensamiento el único posible o el más adecuado para dar cuenta de la experiencia que realmente hacemos a la hora de juzgar las circunstancias puntuales, efímeras y singulares de nuestra vida cotidiana?

A nuestro entender, la propuesta de Pareyson apunta a muy otra perspectiva: no se trata de suponer una ley ya dada, única y objetiva (que, por lo demás, sólo se presenta así, única y objetiva, en tanto que general, genérica o abstracta), sino de reconocer que la ley ha de ser hallada, descubierta, inventada en cada caso, y que esta es precisamente la tarea formativa de la interpretación.

\subsection{La forma formante como guía del proceso formativo}

La forma-obra en la que culmina y descansa toda actividad humana es precisamente resultado, no modelo, de un proceso formativo, y este proceso es esencialmente tentativo: procede por intentos continuamente revisables y revisados cuyo éxito no está garantizado de antemano. La forma, por decirlo así, se va abriendo camino acogiendo a cada paso, entre las muchas posibilidades halladas, ensayadas y descartadas, la que sola le corresponde. Es éste el proceso trabajoso que atraviesa el artista en la formación de su obra, y es precisamente a partir de la experiencia concreta de los artistas que Pareyson llega a formular su estética de la formatividad ${ }^{10}$.

Pero si el proceso formativo es venturoso y constantemente expuesto al fracaso, ¿habrá que concluir que es simplemente aleatorio y falto de toda guía? Y la energía formante del artista, del artesano o del hombre que piensa, decide y actúa, ¿acaso queda confiada tan sólo a su ingenio, gusto o capricho? Según Pareyson, el hecho de que la formatividad no dependa de una regla predeterminada no le impide tener una orientación firme, como sucede en modo ejemplar en la producción de la obra de arte: "Se trata de un proceso en el que el artista va buscando y tanteando, sostenido y orientado por una única certeza: la de que, si la búsqueda fuese compensada por el descubrimiento, si la tentativa culminase en el logro, él sabría inmediatamente que ha dado en el blanco" ". Lo que guía la formatividad es la idea de logro, es decir, la experiencia de que la obra, en la medida en que ha encontrado su forma y alcanzado su cumplimiento, se impone por su propia luminosa, satisfactoria, cabal perfección: "Una operación es formativa en la medida en que de la obra que de ella resulta se puede decir que está bien hecha, no en cuanto que «ha seguido las reglas», sino en

10 En el prefacio a la obra Pareyson afirma que su estética "no es una estética de la contemplación, sino de la producción"; explica que: "Las observaciones de Poe, Flaubert, Valéry, y otros que le son afines, me instaron a estudiar el carácter compositivo y constructivo, calculado y aventurado a la vez, de la actividad artística"; y finalmente añade: “( ...) en el modo en el que he intentado resolver esta dificultad [la dificultad de explicar cómo puedan compaginarse el carácter tentativo del proceso con el carácter orgánico del resultado] me parece poder indicar, además del núcleo de mi investigación, también el lado más novedoso de la teoría que propongo" (ibíd., pp. 1-2).

11 Ibíd., pp. 115-116 (subrayado de Pareyson). 
cuanto que es un «logro», es decir, cuando ha descubierto su propia regla en lugar de aplicar una prefijada. (...) Formar significa «lograr hacer», es decir, hacer de modo que sin apelar a reglas técnicas preestablecidas y predispuestas se pueda y se deba decir que aquello que se ha hecho ha sido hecho como debía hacerse."12

Pero si la forma lograda es el norte del proceso formativo, su función no atañe solamente al último acto (cuando ratifica la bondad de lo que se ha hecho por la evidencia de su propia perfección), sino que lo acompaña desde un comienzo. Es aquí donde Pareyson introduce la distinción fundamental entre forma formada y forma formante. Según nuestro autor, la afirmación de que la forma existe solo como formada no es más que un prejuicio, el cual lleva fatalmente a dos consecuencias opuestas, pero igualmente perniciosas: "por un lado, la ejecución se hace superflua; por otro, la invención se hace imposible. Si la producción no es sino la ejecución de una forma ya formada, todo ha sido ya inventado y descubierto (...). La ejecución que le sobrevenga a la forma ya cumplida se reduce a reproducirla y copiarla (...). $\mathrm{Y}$, si al contrario, la ejecución se abandona a su propio curso, no se entiende cómo pueda extraer de sí la capacidad de orientarse y de inventar"'13. Lo que permite evitar el escollo de esa infructuosa alternativa es aquella inspiración o presagio que marca el inicio del proceso formativo: el motivo. Gracias a él, "la forma -que de todos modos no existirá sino cuando se haya concluido el proceso- ya opera y actúa como guía de aquel mismo proceso del que emergerá en su completitud." ${ }^{14}$ El motivo es una anticipación de la forma futura sin la cual el tantear tendría que moverse a ciegas entre infinitas posibilidades: "En virtud de esta anticipación el tantear es la única operación que sabe conjugar, entre ellas, búsqueda y descubrimiento, las cuales, de otro modo, no se entiende cómo pueden continuarse la una en la otra."15 En tanto que presentimiento o adivinación, el motivo no puede ser traducido en términos de conocimiento, pero ello no le impide tener eficacia operativa como norma interna, inmanente a la ejecución. "Si esta es la naturaleza del proceso artístico -concluye Pareyson (pero también de la formatividad en general, añadimos nosotros) - habrá que decir que la forma, además de existir como formada al término de la producción, actúa ya como formante en el curso de esta. La forma es activa antes que existente"16.

Decir que la forma es activa antes de existir, o que la obra es al mismo tiempo resultado y ley del proceso formativo, suena paradójico. No obstante, observa Pareyson, "El carácter aparentemente paradójico de estos enunciados atestigua que aquí nos encontramos en el corazón del proceso formativo" ${ }^{17}$, de manera que rechazar esa paradoja significa negarse la posibilidad de entenderlo. Pero esa misma paradoja es la que entraña la idea de logro, la que -como se dijo-representa el único criterio del que dispone la formatividad para reconocer paso a paso si lo que va haciendo es o no adecuado: "La dificultad de un análisis filosófico del concepto de logro consiste en esto, en que el logro es tal que solo cuando está cumplidamente realizado muestra claramente su propia ley, mientras antes, cuando aún el proceso está en curso, no hay norma evidente, y esta debe descubrirse en el mismo acto en que se opera." 18

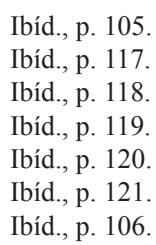


Hay que observar que el concepto de logro no suprime la idea de adecuación como requisito de la verdad, sino que la asume y confirma, aunque sea de manera peculiar. Para precisar tal peculiaridad, cabe aclarar dos cosas: 1) la adecuación no es externa al proceso formativo sino interna; 2) el reconocimiento de que la obra es adecuada (lograda) es experimentado por parte de su autor como cumplimiento de una expectativa.

1) Cuando la forma formada es a la vez forma lograda, entonces podemos decir también que es adecuada, esto es, que corresponde a lo que se buscaba, que es como tenía que ser, que ya no hay que seguir buscando, intentando, corrigiendo, puesto que es perfecta: es una verdadera obra de arte (o bien un utensilio bien hecho, un pensamiento verdadero, una acción virtuosa, etc.). Escribe Pareyson: "El logro, ciertamente encuentra su valor en el ser adecuación perfecta, pero el término con el que tiene que adecuarse no está predeterminado... se trata más bien de inventarlo y de realizarlo, porque aparece, propiamente, como cumplimiento y resultado, de modo que sólo aprés coup muestra su propia necesidad y legalidad." ${ }^{19}$ En otras palabras, la única adecuación necesaria y posible para la formatividad es la adecuación de la obra consigo misma, la correspondencia de la obra a su propia ley interna.

Cabe añadir que si, por un lado, sólo tiene sentido hablar de adecuación en presencia de una instancia objetiva (a la que precisamente hay que adecuarse) y si, por el otro, la adecuación de la que se habla es adecuación de la obra consigo misma, esto quiere decir que la obra posee autonomía e independencia con respecto de su autor, de tal manera que, para éste, no resulta simplemente disponible sino vinculante. Esta necesidad y legalidad que la obra posee en propiedad (y que se impone como norma al mismo autor que la va formando) es aquel aspecto de la formatividad que Pareyson llama receptivo: "en el obrar humano receptividad y actividad son inseparables porque se constituyen la una a la otra." ${ }^{20}$ Volveremos sobre ese asunto fundamental más adelante.

2) Quien puede constatar el logro de la obra es obviamente su autor y esa constatación acontece como satisfacción de una expectativa. Escribe Pareyson: "el artista reconoce cuando ha encontrado lo que buscaba (...) porque aquello que logra colma una expectativa y satisface una exigencia. La ejecución es, por tanto, el incierto camino de una búsqueda, en la que la única guía es la expectativa del descubrimiento." ${ }^{21}$ Es verdad que esta espera, como vimos anteriormente, ha sido despertada por el motivo, que es como el presagio de la obra ${ }^{22}$; pero también es verdad que el motivo no sale de la nada, sino que es como una semilla que sólo puede brotar en un terreno predispuesto, preparado, labrado oculta y largamente por la espera. Explica Pareyson: "Pero esfuerzo, búsqueda y espera los ha habido, aunque sea inconscientes y latentes, como lo demuestra la misma entusiástica e instintiva aprobación con que reconocemos el descubrimiento... Ciertamente, la idea o viene o no viene, no hay voluntad que pueda hacerla nacer o regla que promueva su invención; pero se puede estar seguros de que sin espera no vendría nunca: si el

Ibídem.

Ibíd., p. 23.

Ibíd., p. 116.

A propósito del motivo, del que ya hemos hablado, Pareyson escribe: "antes del evento de la forma hay también algo que la anuncia y la hace presagiar, que tiende a ella y que crea su expectativa (...) y este algo es el «motivo»" (ibíd., p. 118). 
terreno no fuese ya fértil, ninguna semilla lograría fecundarlo"23. En conclusión, la espera que guía el proceso formativo del artista, y que le permite reconocer la forma lograda, es la espera despertada en él por el motivo, pero éste, a su vez, ha sido preparado por la espera paciente, operosa y confiada del artista. Volvemos a encontrar aquí aquel nexo inseparable entre actividad y receptividad que caracteriza la formatividad y sobre el que merece la pena añadir algunas consideraciones.

El término formatividad sugiere inmediatamente la idea de una actividad que alguien lleva a cabo (de manera ejemplar, el artista), pero Pareyson nos desplaza con otra paradoja: "La obra de arte se hace por sí misma, y sin embargo la hace el artista." ${ }^{24} \mathrm{Si}$ en la formación de la obra de arte la actividad del artista resulta obvia, la actividad de la obra por sí misma es quizás menos evidente pero no menos importante. Con respecto a ésta, el papel del artista es más bien receptivo: el hecho de que el motivo surja de manera gratuita e impredecible y que la idea "venga o no venga"; el hecho de que el motivo exija su propio desarrollo y no uno cualquiera; el hecho de que "el motivo es el germen de la obra, es la obra misma en estado embrionario $\mathrm{y}$, por tanto, tiene una intencionalidad totalmente suya, una tendencia a su propia forma, un destino de organización; y esta vocación formal suya se impone a la mente del artista" ${ }^{25}$; todo esto, decíamos, demuestra que la formatividad es una suerte de diálogo entre el artista y la obra, en el que ésta, al igual que aquél, tiene personalidad propia: "Cuando hay motivo, el artista siente que ya no está solo consigo mismo: está en compañía de la obra"; el motivo "le ha salido al paso al artista, y se adueña de su mente estimulándola e incluso obsesionándola." 26 Por un lado, hay el esfuerzo del artista que ensaya, elige y corrige, atravesando continuamente la incertidumbre y el peligro del fracaso; por el otro, está la presencia de la forma formante que orienta el camino, discrimina posibilidades, sanciona el logro.

En conclusión, actividad y receptividad constituyen un proceso inextricable en el que el artista y la obra se van buscando uno a otro porque ya se han encontrado, y cuya tensión sólo descansa en la perfecta coincidencia de la obra lograda. Es precisamente este equilibrio entre receptividad y actividad lo que, según Pareyson, "caracteriza también los momentos más felices del obrar humano, cuando el hombre se siente tanto más libre y creador cuanto más abierto y disponible a fuerzas que, lejos de inducirlo a la inercia, más bien solicitan y estimulan su acción." ${ }^{27}$

Pero el hecho de que la formatividad sea inseparablemente activa y receptiva merece ser subrayado, puesto que, según nos parece, reviste especial importancia para la concepción que Pareyson tiene de la hermenéutica. Si existe una razón para afirmar que el conocimiento es interpretación, esta se fundamenta precisamente en el hecho de que el comportamiento humano es formativo. Pero formar, precisa Pareyson, no es lo mismo que crear: "El obrar humano está caracterizado por el hecho de que no es creativo. De hecho, la iniciativa humana no se inicia por sí misma, sino que es iniciada y comienza su propio movimiento solo en cuanto que se le da un principio." Y añade: "hay en mi libertad, en la libertad que yo soy para mí mismo, una necesidad inicial, que es el signo de mi habérseme dado principio, de mi

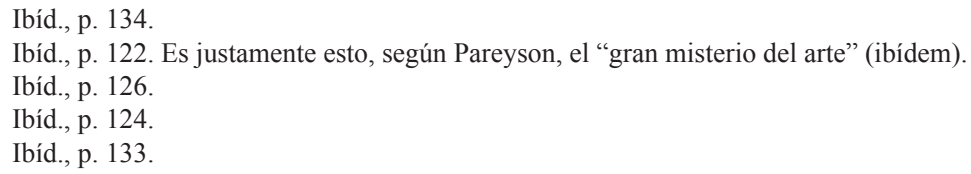


límite, de mi finitud, de una receptividad inicial y constitutiva" 28 . En otras palabras, la receptividad implica que la formatividad siempre tiene que hacer cuentas con una alteridad irreductible y que esa relación le es constitutiva. Así las cosas, para Pareyson la interpretación no puede ser sino del dato: "la interpretación es siempre, a igual título, interpretación de algo, como lo es, siempre, de alguien" ${ }^{29}$; por lo mismo -como justamente ha sido observado- su hermenéutica es una "hermenéutica de la fidelidad" $"$ (al dato).

\subsection{La ejemplaridad de la obra}

"Es característica de todo logro la capacidad de hacerse criterio de valoraciones y apreciaciones y de convertirse en estímulo y norma de nuevas operaciones" 31 : con estas palabras Pareyson no pretende establecer un postulado sino constatar un hecho. Aunque no sea fácil explicar, admite nuestro autor, "cómo la obra, de por sí singular e irrepetible, pueda volverse un modelo", esto es lo que enseña la experiencia: "la historia de cada arte manifiesta con clara evidencia que obras particularmente logradas se han convertido en modelos ejemplares"32. Esto sucede, según Pareyson, porque la obra es singular y universal al mismo tiempo: "La obra de arte es como debe ser y debe ser como es (...) de modo que en ella son una y la misma cosa individualidad y legalidad, determinabilidad y regularidad, ser y deber ser: en otras palabras, singularidad y universalidad." 33

Desde el punto de vista operativo la universalidad de la obra se traduce en ejemplaridad: "el modo en que ha sido hecha se hace paradigmático y (...) suscita tras de sí una serie de recreaciones e imitaciones"34. Pero la imitación de una obra ejemplar no tiene nada que ver con la mera repetición (aunque pueda reducirse a ello), puesto que se trata de una operación nueva y original, de una interpretación que conjuga originalidad y continuidad. La imitación, dice Pareyson, "logra inventar solo continuando y continúa no repitiendo sino inventando, y tanto más inventa cuanto más sabe continuar, y tanto más continúa cuanto más logra inventar." 35 La relación entre la obra ejemplar y la obra que la imita es un vínculo de generación, de filiación, que acomuna una y otra sin comprometer su originalidad, así como sucede en la generación humana, por la que el hijo se parece al padre y, sin embargo, es otra persona.

La repetición es imitación sin invención, formalismo, calco en el que la vida se ha disipado: "La repetición considera la forma como fórmula, el modelo como módulo, la regla como receta, el estilo como cuño, y por tanto es inerte, porque mecaniza la vida parando su movimiento" 36 . Para que la imitación no se reduzca a mera repetición hace falta que la ley inmanente a la obra no sea acatada como una norma ya definida y definitiva (en este sentido, "momificada") sino como un significado

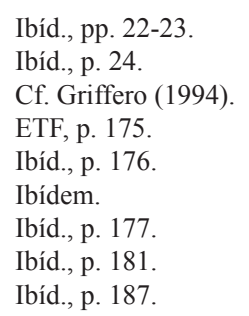


operativo que hay que asimilar por las vías naturales de la filiación. Pero para esto, hace falta también que el autor tenga cierta actitud, asuma cierta postura; en otras palabras, la ejemplaridad de la obra sólo revive en la experiencia viviente del artista. Más adelante tendremos que profundizar en estas últimas dos observaciones (el concepto de imitación y la actitud apropiada que esta exige) para poner de relieve su analogía -según nos parece- con dos conceptos heideggerianos, a saber, el concepto de "repetición" y el de "propiedad".

En tanto que la obra lograda suscita imitación, puede incluso llegar a fundar una tradición; en este caso, de la obra modelo también se van extrayendo patrones, sedimentando pautas, estableciendo reglas. Pero si se olvida ese origen históricoconcreto, si se olvida que las reglas han sido abstraídas de obras singulares y de la concreta operatividad de un artista, se acaba por atribuirles carácter "normativo" como si hubieran sido preexistentes y válidas de por sí, y cuando las leyes adquieren impropiamente ese valor normativo, no cabe más que aplicarlas, seguirlas, observarlas $^{37}$. Ese postura de Pareyson nos parece sumamente interesante porque plantea el origen formativo, y por tanto, histórico-concreto, de los valores (no tan sólo de los valores estéticos, sino de los valores tout court). En efecto, no hay experiencia de los valores si no es a través de formas, y estas no son sino resultado y estímulo de un proceso formativo. De la idea de belleza no es posible "extraer" ninguna obra de arte. Muy al contrario, es a partir de la obra ejemplar como aprendemos algo acerca de la belleza y como una idea de belleza toma forma. Pero esa idea y esa forma no pueden tener sino un carácter histórico-finito, puesto que surgen en el interior de un proceso formativo personal, singular, circunstancial; su validez no es la de la idea platónica, universal e intemporal, sino la de un universal concreto, por llamarlo de alguna manera. La obra ejemplar crea su propio público: funda un gusto, un estilo, una escuela, una tradición; no pretende ser definición sino ejemplo, no pretende ser última sino iniciar un linaje, no pretende ser totalizadora sino estimular una proliferación de formas. Más aún, esta proliferación es virtualmente infinita: una vez ingresada en el mundo, la forma lograda se vuelve fuente, explícita o latente pero permanente, de siempre posibles nuevos inicios.

\section{3. "Imitación" pareysoniana, "repetición" heideggeriana}

Más allá de la obvia diferencia terminológica, nos parece constatar una sustancial afinidad entre lo que Pareyson dice a propósito de la imitación y lo que Heidegger entiende por repetición (Wiederholung).

Para Pareyson, la imitación no es aplicación sino transformación del modelo, sin embargo, aun siendo nueva, no deja aquella de tener afinidad con éste. Explicar cómo sea posible la continuidad en la originalidad y la originalidad en la continuidad no es para nada obvio: "En una verdadera obra de arte, lo que es obvio es, ciertamente, su irrepetible originalidad, y lo que en cambio es difícilmente explicable e indagable es el vínculo de generación que eventualmente la ligue a obras precedentes." ${ }^{38}$ No obstante, esa filiación es un hecho, y este hecho solo tiene lugar cuando el autor, imitando, reinventa las reglas, cuando estas no son para él un marco que constriñe sino una puerta que abre posibilidades inexploradas: "El nuevo autor puede obtener

Cf. ibíd., p. 185 .

Ibíd., p. 183. 
provecho de las reglas siempre que sepa vislumbrar el nexo vivo entre problema y solución, tentativa y logro, proceso y forma (...): sólo así él no las observa sino que las adopta, no las presupone sino que las reinventa, no las aplica sino que las transfiere; y estas vuelven a ser operativas porque renacen como si hubieran sido inventadas por primera vez" 39 .

Para Heidegger, las posibilidades en las que el Dasein efectivamente se proyecta son extraídas del pasado, es decir, heredadas. De entre las posibilidades heredadas, el Dasein sólo elige algunas: las que son dignas de ser repetidas (en términos de Pareyson: imitadas). Pero esa "repetición de lo posible no consiste en la restauración del «pasado» ni en una amarra del «presente» a lo ya «dejado atrás»." 40 En la repetición, el Dasein hace entrega a sí mismo de una posibilidad heredada, pero no se limita a recibirla sino que la escoge en libertad; no la asume tal y como es sino que la "abre" (comprende) de manera propia; no procura que ese pasado vuelva a tener la misma realidad que tuvo en otro tiempo, sino que quiere "ser i n s t a n t á n e o para «su tiempo»" "41. En otros términos, en la repetición acontece la transmisión de un pasado, pero no como Tradition: mera aceptación de un pasado vergangen (muerto e irrevocable), sino como Ueberlieferung: transferencia de un pasado gewesen (siendo sido, aún abierto).

En conclusión, tanto para Heidegger como para Pareyson la auténtica transmisión del pasado es continuidad en la originalidad y originalidad en la continuidad; continuidad -diría Heidegger- no de lo Idéntico sino de lo Mismo.

El hecho de que el Dasein pueda liberar el pasado extrayendo de él posibilidades inéditas supone para Heidegger una condición fundamental: la resolución precursora. Si en la repetición el Dasein "hace entrega de sí mismo a sí mismo en una posibilidad que ha heredado, pero que también ha elegido", ¿en base a qué llevará a cabo esta elección? ¿Cómo llega el Dasein a ver con claridad su situación y a reconocer en ella las posibilidades fácticas del existir propio (las posibilidades dignas de repetición)? En otras palabras, ¿cómo llega el Dasein a escoger su propio héroe al que "imitar"? "Cuanto más auténticamente se resuelva el Dasein, es decir, cuanto más inequívocamente se comprenda a sí mismo desde su más propia y eminente posibilidad en el adelantarse hasta la muerte, tanto más certera y menos fortuita será la elección y hallazgo de la posibilidad de su existencia. Sólo el adelantarse hasta la muerte elimina toda posibilidad fortuita y «provisional» (...) y lleva al Dasein a la simplicidad de su destino [Schicksal]." 42 Destino no es todo lo que nos alcanza y "golpea", sino una indicación que sólo puede captar el Dasein resuelto; es por eso por lo que "el irresoluto (...) no puede «tener» un destino." 43 Antes que la elección, está la opción fundamental por un modo propio de existencia; la repetición, pues, como relación auténtica con el pasado, sólo tiene lugar en la resolución precursora. Escribe Heidegger: "La resolución que retorna a sí, y que se entrega a sí misma [la posibilidad heredada] se convierte entonces en la repetición [Wiederholung] de una posibilidad de existencia recibida por tradición. La repetición es la tradición explícita, es decir, el retorno a posibilidades del Dasein que ha existido. La repetición propia de una existencia que ya ha sido - que el Dasein escoja su héroe- se funda existencialmente

39 Ibíd., p. 186.

40 Heidegger (2002), p. 401 (espaciado de Heidegger).

41 Ibídem.

42 Ibíd., p. 400.

43 Ibídem. 
en la resolución precursora; porque en ella se hace por primera vez la opción que libera para el seguimiento combatiente y para la fidelidad a lo repetible." 44

También para Pareyson "la validez de los resultados de la imitación depende de la capacidad del seguidor en no menor medida que de la dignidad del modelo" 45 , y esto significa que la ejemplaridad, para ser retomada y continuada de manera original, supone cierta condición en el imitador. Esta condición es la congenialidad: "el tipo de originalidad que no sólo no excluye el remontarse a actividades preexistentes, sino que, es más, sabe extraer ventaja de ello, e incluso lo busca para nutrirse de él, es aquello característico de la congenialidad." 46 Pero es importante subrayar que este "feliz encuentro", en el que el imitador sabe captar e interpretar la ejemplaridad de la obra, no deja de ser un acto de elección: "El intento imitativo surge desde el interior de un acto original e independiente: la ejemplaridad, aun siendo intrínseca a la obra de arte, no actúa sino desde dentro del acto que la reconoce, que es ciertamente un acto de elección, una libre adhesión, un autónomo consenso, que sabe extraer una orientación de la obra tomada como modelo solo en cuanto que sigue su propio estímulo y su propio intento." ${ }^{47}$ Así como el Dasein escoge su héroe, también el artista escoge su obra ejemplar: "Este, lejos de haber sido elegido, elige; lejos de dejarse determinar, ha solicitado de su modelo guía y consejo: si la obra ejerce sobre él un influjo, es porque él mismo la ha inducido a ejercerlo." 48 Cualquier cosa puede convertirse en motivo de arte, pero esto solo sucede para el artista consciente, por "la potencia de su mirada formativa" $"$. En el reconocimiento de la ejemplaridad está en juego la personalidad del artista, su entera espiritualidad ${ }^{50}$. En efecto, si bien es verdad que la intención formativa del artista no instituye la ejemplaridad -la cual es más bien inmanente a la obra y posee su propia independencia-también es verdad que ésta, sin aquella, quedaría inactiva, latente, virtual. Pregunta Pareyson: “¿Pero, qué sería esta independencia del motivo sin la actividad del artista, que no solo lo reconoce y acoge sino que lo espera y prepara?"51 En efecto, "el motivo no es nada fuera del reconocimiento que se le da", pero además, "la atención con la que el artista lo fija no es sino una prolongación de la fértil expectativa con la que él lo ha esperado asiduamente" y sin la cual ni siquiera surgiría o simplemente pasaría inadvertido: "La expectativa exige $s u$ motivo, aquel que puede nacer solo ahí, en esa esperanza y atención, en esa preparación y fecundidad, de modo que esperarlo es ya evocarlo". En conclusión, así contesta nuestro autor la pregunta que él mismo planteaba: "Todo, por tanto, en el surgir del motivo depende de la actividad del artista, y solo dentro y mediante esta actividad este puede presentarse y actuar en su independencia." 52 Mirada más de cerca, tal expectativa es una disposición de la entera existencia del artista: "Ahora bien, una espera tan activa y productiva, que, apenas le ocurre lo que esperaba, de inmediato se vuelve a reconocerlo, es la intencionalidad formativa, que el artista ha impreso a la totalidad de su propia experiencia. Es una voluntad de arte,

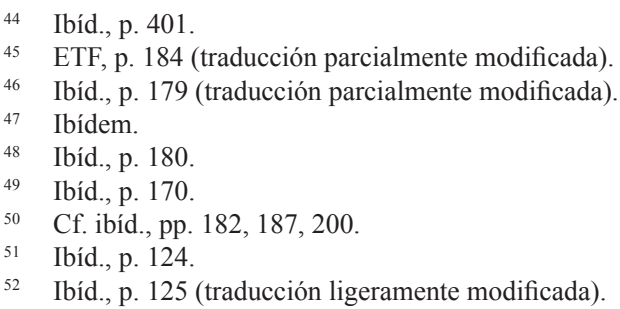


que absorbe en una intencional formatividad toda la vida espiritual, y se convierte en una carga de energía, un modo de ver formando y de mirar construyendo, que convierte en motivos los más mínimos incidentes"53. La personalidad del artista llega a ser sí misma solo cuando ha encontrado su propio modo de formar, es decir, su propio estilo; el estilo es "una espiritualidad que se ha hecho modo de formar" 54 , de tal manera que, "cuando una espiritualidad ha encontrado su propio estilo, esta es ese estilo mismo." ${ }^{55}$ Cuando el artista, en cambio, no posee una espiritualidad propia o no logra afirmarse a sí mismo, la imitación decae a mera réplica.

En conclusión, tanto para Heidegger como para Pareyson la posibilidad de una repetición-imitación auténtica del pasado, que no decaiga a formalismo estéril, pende de una actitud de la persona, por lo tanto, de una resolución o intencionalidad de su libertad. En este sentido, creemos, cabe hablar de una moralidad de la imitación.

Por lo demás, también nos parece encontrar algo más que una analogía entre la dimensión receptiva de la formatividad, de la que habla Pareyson, y el concepto heideggeriano de destino (Schicksal) recién mencionado. En efecto, no tendría sentido hablar de destino si la persona (o el ser-ahí) fuera el único protagonista de la existencia, de la interpretación, de la historia; muy al contrario, el término destino alude a una alteridad presente ${ }^{56}$ y actuante pero indisponible por la persona, con respecto a la que ésta, más bien, tiene que hacerse disponible, justamente receptiva (aunque no simplemente pasiva). La actividad del artista no es separable de la actividad de la forma formante por la que la obra "se hace por sí misma", según su propia ley de evolución, y que el artista más bien ha de recibir, secundar, obedecer: la independencia del motivo, la idea feliz que se presenta "como un don misterioso y puramente gratuito" 57 , que impone las exclusiones y las elecciones según un desarrollo univoco ("el único posible, aquel que quería la obra") ${ }^{58}$... todo esto, pues, indica claramente que en el proceso formativo interviene otro factor que no es la personalidad del artista o, si se quiere, muestra que la formatividad es un diálogo en el que la persona es tan sólo uno de los interlocutores ${ }^{59}$.

\section{Interpretación}

La concepción del conocimiento como interpretación, según Pareyson, es consecuencia implícita e inevitable del carácter formativo inherente a toda actividad humana. Pero ¿en qué sentido la formatividad exige y justifica la interpretación? Escribe Pareyson: "el concepto de interpretación resulta de la aplicación al conocimiento de dos principios fundamentales para una filosofía del hombre: en primer lugar el principio por el cual todo obrar humano es siempre, al mismo tiempo,

\footnotetext{
Ibídem.

Ibíd., p. 86.

Ibíd., p. 87; véase también el apartado Correspondencia e identidad de espíritu y estilo, pp. 79 ss.

56 Somos conscientes de que con solo mencionar esta palabra podemos incurrir en las tantas y fáciles críticas que suelen dirigirse a la "metafísica de la presencia"; sin darle por el momento más vueltas al asunto creemos sea suficiente añadir que "presencia" no significa necesariamente "presencia de un objeto"; de muchas otras maneras, pues, algo se hace presente, es decir, nos alcanza, interpela o afecta.

57 ETF, p. 132.

58 Ibíd., p. 124.

59 Acerca de la naturaleza de este "diálogo" véase el apartado Inescindibilidad de receptividad y actividad en el obrar humano, pp. 22-24.
} 
receptividad y actividad, y en segundo lugar el principio por el que todo obrar humano es siempre personal. ${ }^{\circ 0}$ De ahí que nuestro autor proponga la siguiente definición de interpretación: "interpretar es una forma de conocimiento en la que, por un lado, receptividad y actividad son inseparables, y por otro, lo conocido es una forma y el que conoce es una persona." ${ }^{61}$ Consideremos por separado esos dos aspectos.

1) Ciertamente la interpretación es un acto del interpretante, pero esa actividad no es creativa, como si se tratara de un inicio absoluto, sino justamente formativa, puesto que siempre es interpretación de un dato. La interpretación es esfuerzo por captar, aferrar y penetrar el dato y, en este sentido, es "un ejercicio de fidelidad" ${ }^{62}$. De no ser así tampoco podría considerarse conocimiento. Por otra parte, la interpretación no es puramente pasiva, como si se limitara a reproducir el dato, sino que activamente lo acoge como ocasión y sugerencia para un desarrollo. Cuando el objeto solo se impusiera al sujeto, o bien al revés, cuando el sujeto se superpusiera al objeto, ya no queda espacio para la interpretación: "Si un cosa se me impone hasta el punto de que yo la padezco, o mejor, si yo fosilizo la cosa frente a mí, transformándola en una imposición que no sea ya una propuesta, en una exterioridad que no es ya invitación, en una oposición que me la vuelve impenetrable, entonces no hay interpretación. Pero tampoco la hay cuando yo me superpongo a aquello que tengo que interpretar... rechazando el esfuerzo de fidelidad que constituye la posibilidad de captar la íntima naturaleza del objeto." ${ }^{\circ 3} \mathrm{Ni}$ mera pasividad ni pura creatividad, la interpretación es mutua implicación de receptividad y actividad, de tal manera que, por un lado, no hay iniciativa que no presuponga una ocasión, un estímulo, una propuesta que la ponga en movimiento y la encamine; por otro, "ver una ocasión es ya valerse de ella (...), acoger una propuesta es ya responder a ella (...), recibir un estímulo es ya reaccionar a él: la misma forma de la receptividad es la actividad." ${ }^{64}$ En conclusión, así como en el hombre no hay receptividad sin actividad, tampoco hay actividad más que como prolongación y desarrollo de una receptividad: "En el acto de la interpretación, el oír se hace escuchar y el escuchar quiere hacerse oír; la receptividad se afina a través de la actividad, y la actividad apunta hacia la receptividad: la una y la otra se entrelazan, se alimentan entre sí, se apoyan, se reclaman y se implican mutuamente." ${ }^{65}$

2) El objeto de la interpretación es siempre una forma, y el sujeto, una persona. Es por eso por lo que Pareyson define la interpretación como "conocimiento de formas por parte de personas"66. En tanto que personal, la interpretación posee los mismos caracteres de todo obrar humano, esto es, "plasma y expresa, tiende a concluirse en formas y expresa a la persona que obra." ${ }^{\prime 67}$ Esto se debe a que la persona presenta dos aspectos: totalidad y desarrollo. Escribe Pareyson: "Por un lado, la persona es la obra que yo hago de mí mismo, concluida y definida a cada instante, y por otro es una obra en desarrollo, abierta a la necesidad y exigencia de nuevos actos y nuevos desarrollos. Si se examinan más de cerca estos dos aspectos de la persona se verá

60 Ibíd., p. 22.

61 Ibídem.

62 Ibíd., p. 25.

63 Ibíd., pp. 24-25.

64 Ibíd., p. 23.

65 Ibíd., pp. 25-26. Vale la pena observar que para Pareyson la mutua implicación de receptividad y actividad opera ya a nivel de la sensación, por lo que incluso la intuición es ya interpretación, aunque sea de manera germinal (Cf. ibíd., Cap. II, apartado 7).

66 Ibíd. p. 28.

67 Ibídem. 
que la totalidad conclusa de la persona es la típica definición de la forma, y que la actividad siempre abierta a nuevos desarrollos de la persona es actividad destinada a culminar en formas." 68 En conclusión, la persona es una forma cuyo obrar es plasmador de formas, las cuales, a su vez, expresan la totalidad de la persona.

En tanto que expresiva y plasmadora, la interpretación no se dirige a su objeto como a un dato puramente objetivo, extrínseco e inerte, sino a una forma singular e irrepetible, dotada de vida propia, que el intérprete acoge, aferra y figura según su personalísimo estilo. "Si no fuese así, observa Pareyson, no habría otra forma de conocimiento más que un conocimiento en el que todos deben inmediatamente estar de acuerdo y que es directamente comunicable. En efecto, en este caso el sujeto del conocimiento sería impersonal, universal y trascendental y el objeto quedaría fijado en su misma objetividad, dada o constituida"69. Que las cosas no estén así, observamos nosotros, no hay quien no lo vea. Muy al contrario, reconocer el carácter personal e interpretativo del conocimiento implica la resuelta aceptación de una "explosión" ilimitada de la interpretación: "No tiene sentido ni la unicidad ni el carácter definitivo de la interpretación: supuesta la interpretabilidad se supone con ello al mismo tiempo la posibilidad de infinitas interpretaciones y de un proceso infinito de interpretación; la interpretación es infinita en su número y en su proceso, está caracterizada por una infinitud cuantitativa y cualitativa." 70 Tanto la persona que interpreta como la forma interpretada presentan infinitos aspectos o perspectivas (infinitud cuantitativa) y son susceptibles de infinitos desarrollos (infinitud cualitativa), los cuales, sin embargo, no agotan ni la una ni la otra.

\subsection{Metafísica de la forma e incremento del ser}

Ese crecimiento sin límites del proceso interpretativo descansa sobre el doble presupuesto de que todo es forma (tanto las obras humanas como las cosas de la naturaleza) y de que toda forma constituye un organismo (esto es: una totalidad conclusa, pero que en su definición encierra un infinito; dotada de vida propia, según su interna ley de organización; singular e irrepetible, pero universalmente válida).

Forma es, en primer lugar, la persona: "si una filosofía del hombre es siempre una filosofía de la persona, hay que concluir que no hay filosofía de la persona que no sea a la vez filosofía de las formas. La movilidad indefinida y la condición de ser desarrollo histórico del hombre no son otra cosa que plasticidad, que tiende a plasmarse en formas y a plasmar formas"71. En segundo lugar, forma es también toda obra humana, que adquiere vida propia en tanto que encierra y condensa en sí la vida espiritual del autor: "Hay una trascendencia de la persona respecto de sus propias obras, que como valores históricos viven por sí mismas, singulares y calificadas, pero cada una de estas obras extrae su propia independencia singular y ejemplar justamente de su carácter de personalidad, es decir de su ser resultado de un obrar personal, de una actividad puesta en marcha por una persona en cuanto forma." 72

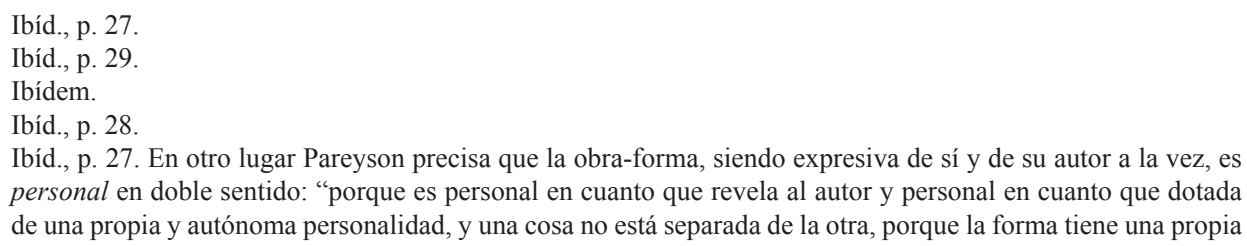
personal en doble sentido: "porque es personal en cuanto que revela al autor y personal en cuanto que dotada de una propia y autónoma personalidad, y una cosa no está separada de la otra, porque la forma tiene una propia 
Finalmente, el hecho de que el conocimiento implique un ejercicio de formatividad "supone que las cosas sean formas, es decir, resultados de una actividad formativa de la naturaleza, organizadora de sus productos y no mecánica en sus fenómenos"73. Más aún, precisa Pareyson, "nuestro conocimiento no sería figuración y formación, es decir, no sería interpretación, si la naturaleza no formase y figurase a su vez, y justamente porque la naturaleza posee un carácter plasmador el conocimiento que de ella tenemos tiene un carácter formativo." Por eso puede decirse que "la interpretación es la prolongación del mismo nisus formativus de la naturaleza, que solamente en tal prolongación resulta conocible" " En conclusión, "en una filosofía de la persona vínculos indisolubles entrelazan una estética de la formatividad, una gnoseología de la interpretación y una metafísica de la forma." 75

Por otra parte, según Pareyson, en el arte encontramos, "en estado puro y exaltada en sus máximas posibilidades, aquella actividad formativa que [el hombre] de algún modo ejercita en todas sus operaciones, y sin la cual no podría alcanzar ningún valor." ${ }^{\prime 76}$ En otras palabras, los valores no existen de manera puramente ideal, sino que cobran existencia en tanto que resultado de un concreto proceso formativo. Eso es evidente en el caso de la obra de arte ("su misma existencia es un valor" que posee independencia, originalidad y unitotalidad, pero también aplica a toda operación humana, puesto que "estos caracteres constituyen la estructura misma del «realizar» (...) En definitiva, -subraya nuestro autor- realizar significa no tanto existenciar un valor, singularizar un universal, concretar un infinito, cuanto más bien producir una existencia válida, un individuo «omni-reconocible» y ejemplar, una definición inagotable e infinita." ${ }^{78}$ Ese subrayado nos parece importante porque conlleva la inversión de aquella concepción que hemos llamado deductiva: no es a partir de los valores que se "deduce" el realizar, sino que los valores se producen a través del realizar (de ahí también que los valores tengan carácter histórico-finito).

Así como las obras de arte se añaden a las cosas naturales también nuestras interpretaciones trascienden, enriquecen y ensanchan los confines del mundo. Escribe Pareyson: "tanto las cosas de la naturaleza como las obras de arte son formas, lo cual demuestra la potencia del espíritu humano, el cual, siendo capaz de «hacer ser» productos orgánicos y realidades vivientes, puede extender los límites del reino de las formas, añadiendo a las formas naturales, sin solución de continuidad, aquellas inventadas por él mismo"79. Y añade: "tampoco el conocimiento y la contemplación se sustraen a la naturaleza del espíritu humano, que está destinado a incrementar el valor del universo, porque estas revelan las cosas solo rehaciéndolas, y rehaciéndolas desde puntos de vista siempre distintos." ${ }^{80}$ No es posible conocer la realidad sino rehaciéndola, formándola, configurándola, y en esto consiste la interpretación. Desde el punto de vista hermenéutico, pues, la necesaria y posible objetividad del conocimiento no puede apelar a puros hechos, independientes de

personalidad solo si persona es su autor" (ibíd., p. 265).

73 Ibíd., p. 261.

74 Pareyson (2005), p. 217.

75 Ibíd., p. 218. Como justamente observa Riconda, Pareyson no ha desarrollado una tal metafísica, pero la perspectiva abierta nos parece prometedora y digna de ser retomada. Cf. Riconda (2011), p. 14.

76 ETF, p. 257 (subrayado nuestro).

77 Ibíd., p. 258.

78 Ibídem.

79 Ibíd., p. 159 (subrayado nuestro).

80 Ibíd., p. 262 (subrayado nuestro). 
toda subjetividad, ni pretender (por lo demás, sin lograrlo nunca) adecuarse a ellos sin residuos. Si alguna adaequatio (correspondencia, dependencia, vinculación al dato) tiene que haber, esta no puede entenderse como reflejo. Escribe nuestro autor: "si el conocimiento de las cosas implica un ejercicio de formatividad, esto quiere decir que las cosas, lejos de imponerse determinando un reflejo de sí mismas o de reducirse a meras construcciones del espíritu humano, se ofrecen a reclamar y solicitar ser «interpretadas», y que conocer no significa ni padecer ni crear, sino revelar y rehacer la realidad" 81 .

Puesto que conocer no significa padecer (adecuarse pasivamente a) ni crear (producir absolutamente) sino configurar (rehacer, interpretar) la realidad, la hermenéutica de Pareyson no es ni una "metafísica de la realidad ya cumplida" ni una "metafísica de la creatividad" sino una "metafísica de la figuración". La primera, en efecto, no admite la actividad del proceso formativo: "la realidad está ya concluida y es perfecta, no se la puede innovar ni aumentar con una producción de realidad y de valor, ya que el valor coincide con el ser, y toda innovación de la realidad es como mucho reproducción y reelaboración" 82 . La segunda, en cambio, no reconoce la dimensión receptiva de la formatividad. Solamente la tercera, pues, en tanto que mantiene unidas actividad y receptividad, puede dar razón del obrar humano tal y como es: personal, singular, tentativo, innovador, válido, histórico.

\section{Conclusiones}

Si la hermenéutica tiene una justificación, a nuestro entender esta descansa sobre el supuesto de que el conocimiento es formativo: no se limita a reproducir un estado de cosas objetivo, sino que lo rehace de manera siempre distinta, personal, inédita. La interpretación, pues, trae consigo un "valor añadido", una novedad que transfigura el mundo, enriquece la realidad, incrementa el ser.

La postura de Pareyson nos parece valiente porque asume tal supuesto sin reparos, haciéndose cargo de los problemas y los riesgos, pero también de las potencialidades que tal radicalismo hermenéutico conlleva.

Formativo es el conocimiento porque formativa es toda la operatividad humana. La caracterización de la existencia como un formar, obrar, realizar, nos viene a decir que vida y mundo no representan un dato acabado que sólo cabría acatar, registrar, secundar, sino más bien una tarea; no están ya hechos, sino por hacer, y en esto consiste la vocación única y singular de la persona ${ }^{83}$.

Pero "formar", precisa Pareyson una y otra vez, no es lo mismo que "crear": la formatividad es constitutivamente receptiva, además de activa, porque el hombre es un ser finito, dado a sí mismo, originariamente en relación con un dato, en última instancia, con el ser. Por consiguiente, también la interpretación es inseparablemente actividad y receptividad, expresión y revelación: así como no hay iniciativa que no haya sido puesto en marcha por un motivo, guiada por un presentimiento, sancionada por un logro, del mismo modo, no hay revelación si no desde dentro y a lo largo de un proceso tentativo.

\footnotetext{
Ibíd., p. 261.

Ibíd., p. 67.

En este sentido, para Pareyson el tener que ser heideggeriano es propiamente un tener que hacer.
} 
Pero ¿cuál es el valor de la interpretación en tanto que resultado personal de un proceso formativo? Se trata, dice Pareyson, de un valor ejemplar: en la medida de su logro, cada interpretación deja una huella, establece un ejemplo que puede ser imitado, que crea su propio público y eventualmente funda una tradición. Semejante validez puede parecer "poca cosa", sin embargo, no son "otra cosa", sino justamente obras, los cimientos sobre los que una civilización ha sido levantada y descansa ${ }^{84}$. La validez de la interpretación, pues, es radicalmente histórico-finita, vinculada no tan sólo a su propio tiempo sino también a una personalidad concretísima, a una idiosincrasia determinada, limitada, singular: no hay obra alguna -texto o artefacto, empresa o institución- que no lleve nombre y apellido (aun cuando nombre y apellido hayan caído en el olvido); no obstante, la obra lograda se impone, y ese logro da fe de su verdad, constituye una auténtica revelación del ser.

En la hermenéutica de Pareyson, singularidad e historicidad - es decir, tanto la persona en su irrepetible individualidad como el conjunto de circunstancias también singulares, variables y efímeras en las que se encuentra- dejan definitivamente de representar un obstáculo y se tornan condiciones imprescindibles y positivas del conocimiento ${ }^{85}$, puesto que configuran la apertura en la que se manifiesta la inagotable riqueza del ser. Singularidad e historicidad, pues, son aquellos fenómenos que sólo la hermenéutica puede asumir, explicar y valorar, y que, justamente por eso, la legitiman.

Por último, quisiéramos hacer unas breves referencias a la hermenéutica de Heidegger, con respecto a la cual -según nos parece- la propuesta de Pareyson representa un desarrollo original y ofrece más de una ventaja. En primer lugar, la formatividad nos ayuda a entender concretamente la manera en que el hombre, como dice Heidegger, configura mundos. En segundo lugar, el acontecimiento del ser, que para Heidegger representa un evento excepcional, epocal (y un tanto "aristocrático", puesto que sólo tiene lugar en la palabra del poeta o del pensador esencial), desde el punto de vista de Pareyson se torna acontecimiento cotidiano (puesto que la formatividad caracteriza toda operación humana) virtualmente accesible a toda existencia (puesto que cada persona es el destinatario de una singular revelación del ser). En cierto sentido, pues, la fundación de un mundo (su inicio, o mejor aún, su re-inicio) acontece en cada gesto plenamente humano. Obviamente, esto no sucede de manera automática, sino que siempre y de muchas maneras está expuesto al fracaso, esto es, al riesgo de la libertad; de ahí que la validez de la interpretación (su logro) viene a depender de una disposición del interpretante, de una actitud de la persona que es, en último análisis, un asunto moral. Si esto es así, la hermenéutica no puede ni tiene porqué aspirar a ser "ciencia rigurosa", sino que más bien se acerca al terreno del arte: arte de lo humano, sabiduría. Esto no quiere decir que la hermenéutica, finalmente entregada a la idiosincrasia de cada persona y a las vicisitudes concretísimas, impredecibles e incluso ambiguas de su biografía, carezca de todo método y esté abocada al arbitrio; simplemente, el criterio o la ley que gobierna la formatividad no puede ser impersonal (y en este sentido, "objetiva")

84 Piénsese, por ejemplo, en algunos textos eminentes, tales como los poemas homéricos, la Biblia o el derecho romano, que han contribuido a plasmar un mundo, un pueblo, una época.

85 Para Pareyson, como ya para Heidegger, la finitud no tiene nada que ver con la negatividad (en el sentido de imperfección, falta o defecto). En propósito, así escribe Cristina Coriasso: "Pareyson propone un existencialismo personal que convierte la situación no ya en impedimento, sino en conditio sine qua non de todo conocimiento", Coriasso Martín-Posadillo (2014), p. XIV. 
sino que ha de ser hallado-inventado en cada caso, puesto que sólo se manifiesta y reconoce desde dentro del proceso formativo: se reconoce porque se inventa, y se inventa porque se reconoce, se descubre haciendo, y se hace habiendo descubierto.

En conclusión, la Estética de Pareyson tiene el mérito de delinear una clara hipótesis de trabajo y de desarrollarla con honestidad y radicalidad. Su propuesta hermenéutica no resuelve todos los problemas, pero ofrece algunas respuestas convincentes -en particular, con respecto a las cuestiones de la singularidad y la historicidad-además de encerrar potencialidades todavía inexploradas - por ejemplo, la posibilidad de transformar el "conflicto" de las interpretaciones en un "concierto", justamente a partir del reconocimiento del carácter personal e histórico, además que inagotable, de la verdad. Todo esto, lejos de señalar una hermenéutica en "fase terminal" - por agotamiento de sus posibilidades o de su función histórica- merece ser retomado y profundizado ${ }^{86}$; más aún, diríamos, en el contexto actual, donde las "viejas" verdades se han derrumbado y las "nuevas" no acaban de nacer. En este mundo cada vez más globalizado, pero también "liquido", pluralista y complejo, el diálogo entre las interpretaciones parece ser el único camino viable para la convivencia y la edificación de una nueva civilización.

\section{Referencias bibliográficas}

Ciglia, F. P. (1995): Ermeneutica e libertá. L’itinerario filosófico di Luigi Pareyson, Roma, Bulzoni.

Coriasso Martín-Posadillo, C. (2014): Introducción a Pareyson, L. (2014): Estética. Teoría de la formatividad, Madrid, Xorki, pp. XIII-XXIV.

Griffero, T. (1994): "Ermeneutiche della «fedeltà»: il dialogo mancato tra Emilio Betti e Luigi Pareyson”, Discipline filosofiche, 2, pp. 105-147.

Heidegger, M. (2002): Ser y tiempo, traducción de Jorge Eduardo Rivera, Santiago de Chile, Editorial Universitaria.

Marino, F. (2015): L'esplicito inesauribile. Pareyson e la storiografia filosofica, Milano, Mimesis.

Pareyson, L. (2005): Estetica. Teoria della formativitá, Milano, Bompiani.

Pareyson, L. (2014): Estética. Teoría de la formatividad, Madrid, Xorki.

Riconda, G. (2011): Pareyson. Persona e libertá, Brescia, La Scuola.

Vattimo, G. (2014): Prólogo a Pareyson, L. (2014): Estética. Teoría de la formatividad, Madrid, Xorki, pp. IX-XI.

86 Es esta también la opinión de Gianni Vattimo: "La realidad no es el darse panorámico de una serie de objetos «out there», ahí fuera, que el ojo de la mente reflejaría (...), sino el evento siempre individual de un encuentro en el que la «captabilidad» objetiva de aquello que se ha encontrado se hace sentir como un «hecho» en la vida del intérprete y no como el tomar conciencia de un orden extraño contra el que uno chocara. Leer o re-leer la Teoría de la Formatividad siguiendo este hilo conductor significa, por tanto, no solo hacer de ella el centro de un nuevo modo de considerar filosóficamente la experiencia del arte, sino también el abrirse uno mismo la vía para una comprensión ontológica del significado de la Hermenéutica en el pensamiento actual", Vattimo (2014), pp. $\mathrm{X}-\mathrm{XI}$. 